TITLE:

\title{
An observation of a severely disabled infant chimpanzee in the wild and her interactions with her mother
}

\section{$\operatorname{AUTHOR}(S)$ :}

Matsumoto, Takuya; Itoh, Noriko; Inoue, Sana; Nakamura, Michio

\section{CITATION:}

Matsumoto, Takuya ...[et al]. An observation of a severely disabled infant chimpanzee in the wild and her interactions with her mother. Primates 2016, 57(1): 3-7

\section{ISSUE DATE:}

2016-01

URL:

http://hdl.handle.net/2433/201516

\section{RIGHT:}

The final publication is available at Springer via http://dx.doi.org/10.1007/s10329-015-0499-6.; The full-text file will be made open to the public on 9 November 2016 in accordance with publisher's 'Terms and Conditions for Self-Archiving':; This is not the published version. Please cite only the published version.; この論文は出版社版でありません。引用の際 には出版社版をご確認ご利用ください。 
NOTICE: This is the author's version of the following article.

Matsumoto T, Itoh N, Inoue S, Nakamura M 2015. An observation of a severely disabled infant chimpanzee in the wild and her interactions with her mother. Primates DOI 10.1007/s10329-015-0499-6

(C) Japan Monkey Centre and Springer-Verlag. The original publication is available on SpringerLink at http://link.springer.de.

\title{
An observation of a severely disabled infant chimpanzee in the wild and her interactions with her mother
}

\author{
Takuya Matsumoto ${ }^{1, *}$, Noriko Itoh $^{2}$, Sana Inoue ${ }^{3}$, Michio Nakamura $^{2}$ \\ ${ }^{1}$ Graduate School of Science, Kyoto University, Kitashirakawa-Oiwake-Cho, Sakyo, Kyoto, 606-8502 Japan \\ ${ }^{2}$ Wildlife Research Center, Kyoto University, 2-24, Tanaka-Sekiden-Cho, Sakyo, Kyoto, 606-8203 Japan \\ ${ }^{3}$ Kamakura Women's University, 6 Chome-1-3 Ōfuna, Kamakura, Kanagawa, 247-0056 Japan \\ *Correspondence author: Phone: +81-75-753-4085; Email: matsumoto@jinrui.zool.kyoto-u.ac.jp
}

\begin{abstract}
We report the physical and behavioral development of one severely disabled female infant chimpanzee (Pan troglodytes schweinfurthii) of the well-habituated M group in the Mahale Mountains National Park. We documented interactions between the infant and its mother and with other group members. Congenital disabilities occur in many primate species, including chimpanzees. However, there have been only a few case studies of congenitally disabled chimpanzee infants and no reports examining how a chimpanzee mother copes with such a disabled infant in the wild. The observed infant exhibited symptoms resembling Down syndrome, similar to those reported previously for a captive chimpanzee. The mother did not allow nonrelatives to take care of the infant even though she had been previously relatively tolerant of allomothering by nonrelatives. The mother's compensatory care for her infant's disabilities and allomothering of the infant by its sister might have helped it to survive for 23 months in the wild. Other group members did not show any aversive or fearful reactions to the disabled infant.
\end{abstract}

Keywords: Mahale Mountains National Park; Chimpanzee; Congenital malformation; Mother-infant relationship; Disability care; Development

\section{Introduction}

Congenital disabilities occur in many primate species. Wilson and Gavan (1967) reported 13 cases of congenital malformations among 2950 deliveries of 12 captive primate species, including chimpanzees (Pan troglodytes: 1 malformation in 172 deliveries). Two cases of disabled chimpanzee infants that survived for 1-2 years in captivity because they received care from humans have been described. McClure et al. (1969) reported that a captive female infant chimpanzee had clinical, behavioral, and cytogenetic features similar to those observed in human Down syndrome. She exhibited slower somatic growth and behavioral development than other laboratory-reared chimpanzees and had some malformations, such as malformed fingers. She was reared by humans because the mother neglected her, and she died at 17 months during a surgical procedure (McClure et al. 1973). Another captive female infant chimpanzee had locomotive failure of her legs and malformation of the thoracic vertebrae (Kumazaki et al. 2010). She was given constant blood transfusion 396 days after birth 
and died at 756 days old. The mother neglected the infant at first but accepted her after 10 days with human support. The mother often pulled out her own hair, suggesting that she might have experienced some stress from holding the infant all day, especially after the infant had grown relatively large (Kumazaki et al. 2010). Although these reports from captivity provide us with detailed symptoms in particular cases, less is known about how disability affects infant development and maternal care for disabled infants in the wild in contexts without active human support.

Possible birth defects, mostly slight ones, have been reported among wild chimpanzees. At Bossou, Guinea, it was observed that a 7-year-old female could not walk properly because of the inability to stretch her thin legs, although she could engage in suspensory locomotion and was able to hold on to her mother's back while being carried (Sugiyama 1984, 2008). Her locomotor impairment had not been noticed in infancy because she was always carried on her mother's back. No subsequent information was available because she either died or disappeared from the area. One female at Gombe, Tanzania, had a malformation of the right foot, probably clubfoot, and sometimes had difficulty keeping up with others (Goodall 1986). However, her limb malformation was not fatal, and she successfully gave birth to two infants.

There is relatively more information regarding acquired disability in wild chimpanzees; disabilities caused by snare injury have been reported at many study sites of wild chimpanzees in Africa (e.g., Quiatt et al. 2002). Research on wild chimpanzees with injuries has generally focused on the effect of manual disability relating to feeding skills (Stokes and Byrne 2001; Byrne and Stokes 2002): it appears that chimpanzees with a manual disability often use the same repertoire of feeding techniques as nondisabled individuals rather than employ entirely novel techniques. Additionally, some chimpanzees suffered physical impairments as aftereffects of a polio epidemic in Gombe (Goodall 1986). Kummer and Goodall (1985) noted that polio-stricken chimpanzees developed new patterns of locomotion: a male who lost the use of his legs managed to move from place to place by a series of somersaults; an infant with polio showed an odd form of locomotion during solitary play. Although these studies describe specific physical disabilities and individual compensatory behaviors associated with those disabilities, little is known about social responses to disability or how disability may influence social behavior of the disabled individual. In that respect, the Japanese macaque (Macaca fuscata) has been investigated extensively. Fedigan and Fedigan (1977) gave a detailed case study of an infant Japanese monkey of the Arashiyama West troop in Texas, USA, focusing on interaction with group members and in comparison with a healthy infant. In the Japanese macaque group in Awajishima, Japan, $16.1 \%$ of infants were born with some congenital limb malformations (Turner et al. 2008). 
Researches at this field site showed that additional maternal-care behavior, such as the mother's physical support-carrying her infant for a longer period-might compensate for the infant's disability and contribute to its survival (Nakamichi et al. 1983; Nakamichi 1986; Turner et al. 2005). Research on maternal care of disabled infants is useful for developing our understanding of maternal investment and behavioral flexibility in a context in which the amount, type, and duration of care do not fit the usual patterns associated with infant development. Here we report one case of a congenitally disabled infant chimpanzee in the wild, providing details of its physical and behavioral development, focusing especially on how the mother dealt its disability and how group members treated it.

\section{Methods}

The subject was a female infant chimpanzee (hereafter XT11) of the well-habituated M group in the Mahale Mountains National Park, Tanzania (Nakamura et al. 2015).

Behavioral data for the infant and the mother were collected during 2011-2012 by focal follows and ad libitum observations. These data were compared with those of a healthy male infant, Omali (OL), who was born in the same month as XT11.

\section{Results}

XT11 was born on 26 or 27 January 2011. She presumably died between 14 and 28 December 2012, at 23 months old. Her mother, Christina (XT), was 36 years old (estimated) when she gave birth. She had given births five times previously and successfully reared two offspring to sexual maturity (Table 1). No congenital physical impairments were recorded for XT or her other offspring.

Table 1 Birth history of the mother of a severely disabled infant chimpanzee (XT11)

\begin{tabular}{lllll}
\hline Name $^{\text {a }}$ & Abbreviation & Sex & $\begin{array}{c}\text { Year of } \\
\text { birth }\end{array}$ & Remark \\
\hline- & XT93 & Male & 1993 & Died in 1993 \\
Christmas & XM & Male & 1995 & Adult in 2011-2012 \\
Xantip & XP & Female & 2000 & Adolescent in \\
& & & & 2011-2012 \\
- & XT05 & Female & 2005 & Died in 2006 \\
- & XT08 & Male & 2008 & Died in 2010 \\
- & XT11 & Female & 2011 & Subject of this study \\
\hline
\end{tabular}

${ }^{a}$ At Mahale, infants are not named until they are 3 years old because of high infant mortality. For abbreviations of those unnamed infants, we use the mother's abbreviations plus the latter two digits for the birth years 
Fig. 1 The disabled infant, XT11 (left), and normal infant of the same age, OL (right)

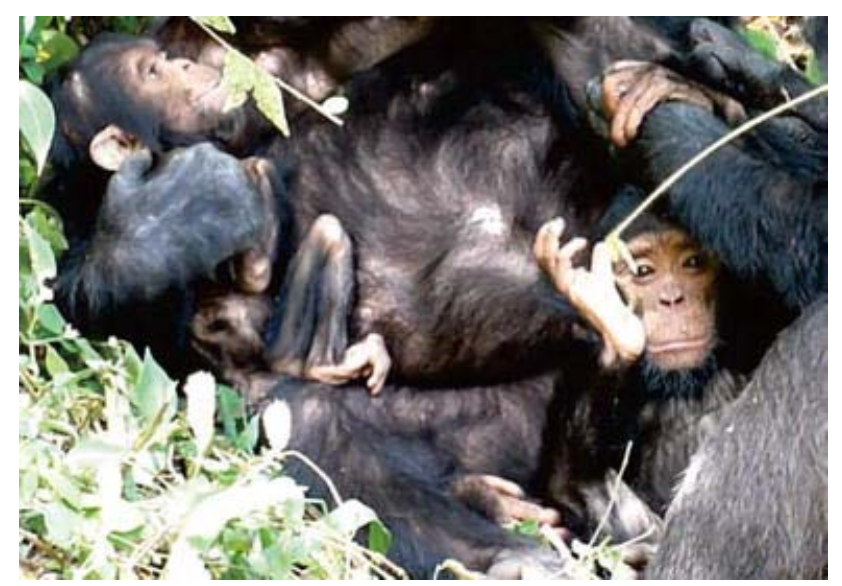

Fig. 2 Abnormal features of XT11. a Empty eyes and half-open mouth (9 months). b A mass on her belly (11 months). c Lying on the ground while the mother (left rear) grooms another individual nearby (6 months). d An extra digit on her left hand (10 months). e XP holds XT11. f Bald patch along the spinal cord (10 months); XT11 is held by XP upside-down
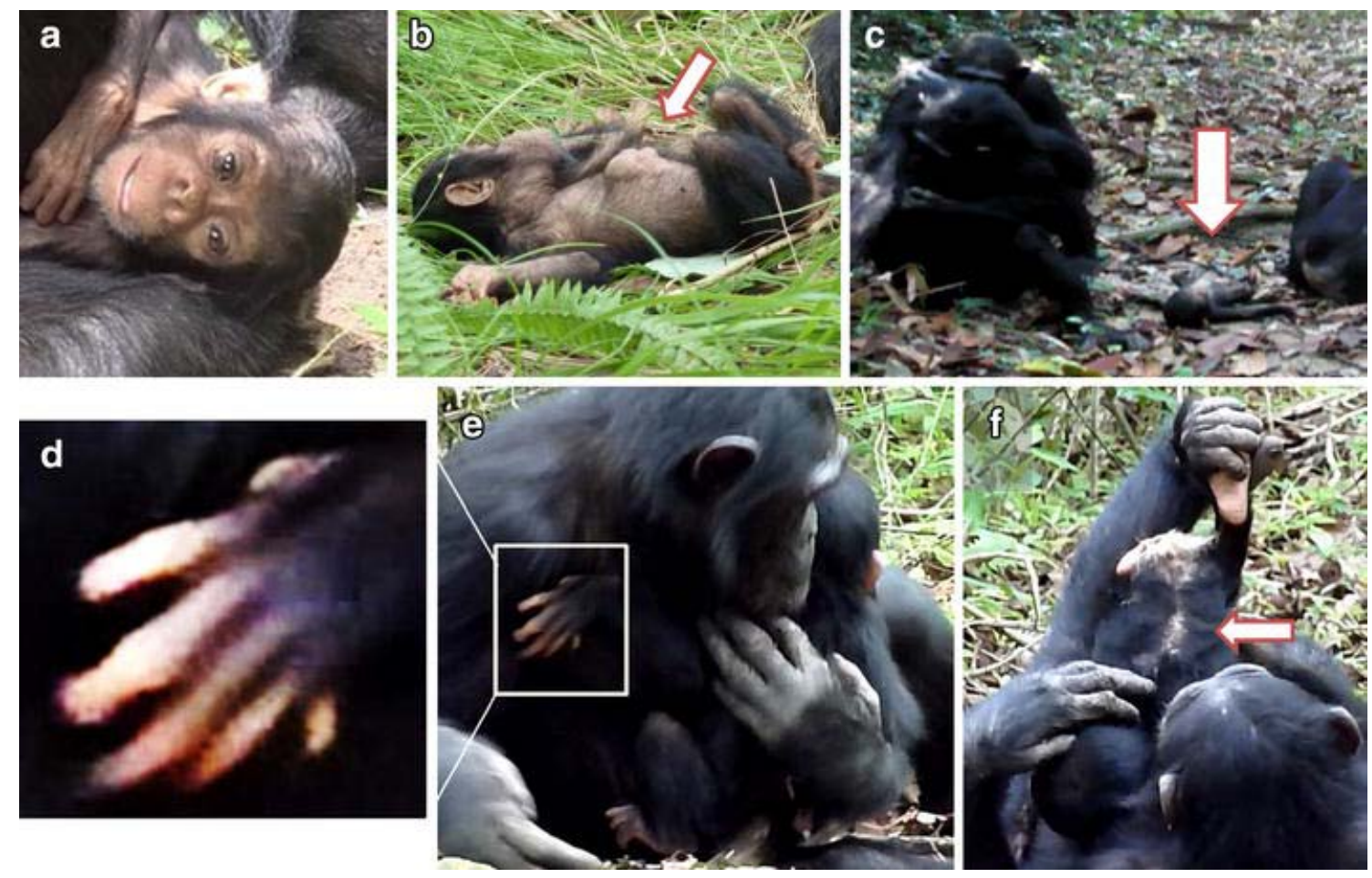

On 18 February 2011, we first noticed that XT11 showed signs of some congenital disabilities because she often released her footgrip from XT's hair when XT was traveling. XT11 had a poorer coat and thinner legs compared with OL (Fig. 1). 
After careful observation, several abnormal physical characteristics were detected. Her eyes looked empty and her mouth was often half open (Fig. 2a). Furthermore, the infant had a mass (probably an abdominal hernia) on her belly, which sometimes changed in size (Fig. 2b). In addition, she had a small extra digit distal to the fifth finger of her left hand (Fig. 2d), which seemed to be an inactive floating finger because it bent downward when other fingers were in upward positions. There was a bald patch on her back along the spinal cord (Fig. 2f).

When XT11 was about 6 months old, her activities did not differ greatly from those of OL (Fig. 3). In her 22nd month, however, her activities showed little change from when she was a young infant, whereas OL became more active. Although data are too sparse to draw firm conclusions, this matches our general impression that XT11 seemed to be less active than typical infants of this age.

Fig. 3 Comparison of activities between XT11 and OL. Data were collected at 5-min intervals for 1 day each, excluding periods when they were carried by another individual. Nipple nipple contact, Rest held by another individual and lying on the ground, Sit Alone sitting by itself, Feed mouthing a part of a plant, Social Play playing with another individual, Others other activities such as moving near the mother

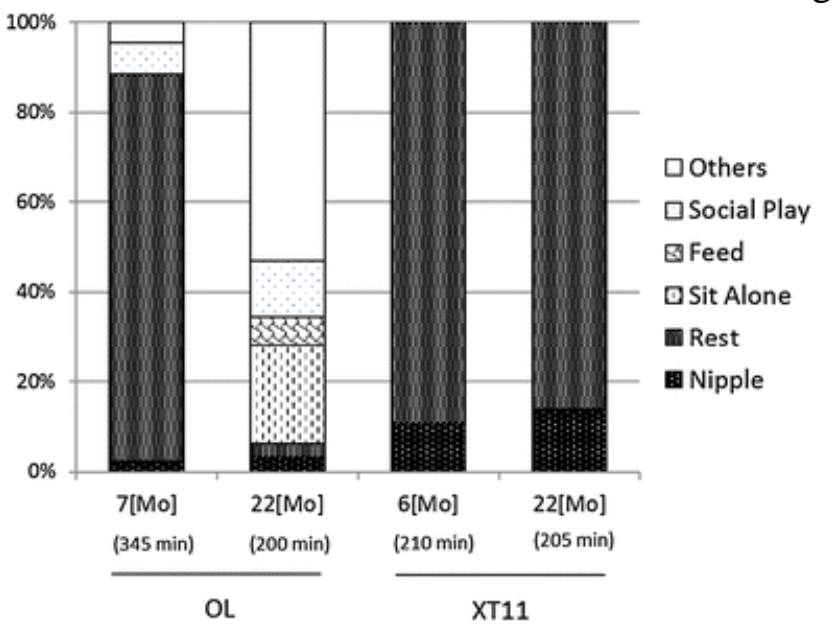

XT11 often lay on the ground or on her mother's lap while resting. Usually, a healthy infant can sit up by itself no later than 6 months old, but XT11 did not do so until her 20th month. We never observed her walking by herself or eating plant materials. Additionally, most chimpanzee infants change/alternate the suckling nipple during a suckling bout. However, XT11 did not do so. XT always needed to support XT11 with an arm and place XT11 on her breast before suckling. Whenever XT walked on the ground, she carried XT11 on her belly. The infant could grasp XT's hair with her hands but did not seem to have enough strength in her feet to grip. Thus, her legs often dangled. Since XT needed to support XT11's lower body with one hand, she walked 
tripedally. When climbing trees, XT always supported or sometimes suspended XT11 in the air by holding XT11's arm with her own hand. This disturbed XT's arboreal feeding to some extent. For example, on 18 December 2011, we observed that XT gave up arboreal ant fishing because she had to suspend herself by one arm and support the infant with the other. When XT groomed with others on the ground, she often put XT11 supine on the ground (Fig. 2c).

XT11's elder sister Xantip (XP), 10-11 years old at the time, often took care of XT11 by handling, carrying, playing with, and grooming her (Fig. 2e, f). XT sometimes spontaneously left XT11 to XP (by approaching XP or pulling her arm), especially before feeding. During 881 min of observation when XT11 was 10-11 months old, XP took care of XT11 for 124 min (14 \%). We did not see XP provide care to XT11 after the former gave birth in November 2012.

Other individuals' behavior toward XT11 was not unusual compared with their behavior toward healthy infants. They sometimes tried to touch or look at her, but XT did not allow nonrelatives to groom or carry her; her older brother, Christmas, was not observed to groom or carry her but was once seen to dangle her when he groomed with XT.

\section{Discussion}

Our observation adds to the knowledge of congenital disabilities among wild chimpanzees and is the first detailed report of maternal responses to a disabled infant. Precise diagnoses are rarely possible in the wild, and it is difficult to determine exact causes because such impairments can result from several factors (Sugiyama et al. 2014). The small size of XT11 compared with OL was probably caused by her disability, because there is no remarkable sex difference in body size in chimpanzee infancy (Hamada et al. 1996). Her physical development, such as motor abilities, seemed to be slow compared with other infants of the same age. The observed syndrome, which included a possible delay in neurologic development (as inferred from her facial expressions), general inactivity, and lack of ability to sit up earlier than 20 months, was similar to that reported for a captive chimpanzee with Down-like syndrome (McClure et al. 1969, 1973).

Stokes and Byrne (2001) indicated that chimpanzees with a manual disability used the same repertoire of feeding technique as healthy individuals. However, XT11 was never observed to eat plant foods and thus completely depended on her mother's milk for nutrition, even after the age at which healthy infants start to feed by themselves (Hiraiwa-Hasegawa 1990). XT11 might have needed less nutrition than healthy infants because she never traveled alone or played actively. However, we suspect that her 
feeding limitations were due to her lack of motor ability and that she might have suffered from a lack of nutrition because of her milk diet, at least in her latter life.

Although the cause of XT11's death is unknown, the mother's unusual treatments (such as laying her on the ground) or the infant's poor nutrition are potential causes. The mother of a severely disabled infant probably experiences more stress than other mothers because she must provide intensive care for longer, as we see in case of captivity (Kumazaki et al. 2010). XP's temporal caregiving might have relieved her stress to some extent, as we observed that she seemed to leave XT11 to XP before feeding, in particular. Therefore we speculate that XP's caregiving had some positive effect on XT11's survival. It is also possible that termination of XP's caregiving might have increased XT's burden of rearing the infant.

The mother's physical support in carrying her infant while traveling and climbing indicates that she responded to XT11's abnormal behaviors, limited abilities, and needs. This kind of compensatory care was like that described for Japanese macaques ( $M$. fuscata) (Nakamichi et al. 1983; Nakamichi 1986; Turner et al. 2005). XT had to carry XT11 ventrally all the time, support her with a hand and walk tripedally, support her posture on trees, place her on her breast before suckling, and put her on the ground while grooming. Without this kind of unusual and flexible maternal care, XT11 might not have survived for her entire 23 months in the wild.

We should point out that XT did not allow nonrelatives to carry XT11, although XT had previously been relatively tolerant of allomothering by nonrelatives (Nakamura 2010). As there was no evidence that other individuals showed any aversion to or fear of the disabled infant, XT's intolerance might have been due to understanding that her infant required unusual extra care and that letting others carry the infant was unsafe. Against an argument that conspecific care is indispensable for survival of disabled individuals in ancestral human society (e.g., Doat 2014), studies of extant nonhuman primates question this notion, as some disabled individuals survive without such care (Struhsaker et al. 2011; Turner et al. 2014). However, those studies focused on conspecific care in adulthood. Conversely, our data contribute to acquiring insights about conspecific care during infancy, the period in which maternal care is most needed (but see Nakamichi et al. 1983; Turner et al. 2005). In our case, nonmaternal conspecific care by kin, but not by nonkin, was observed. Although we cannot presently conclude that nonkin care is totally absent in chimpanzees, if it is, such care might have been somehow expanded from kin to nonkin and from infancy to adulthood during the course of human evolution. Further information is needed to fully understand the nuances of conspecific care for individuals with disabilities among nonhuman primates. 


\section{Acknowledgments}

We thank the Tanzania Commission for Science and Technology, the Tanzania Wildlife Research Institute, the Tanzania National Parks, and the Mahale-Gombe Wildlife Research Centre for permissions to conduct this research at Mahale; and Tanzanian assistants for their daily help in the field. We thank Mr. T. Udono and Dr. M. Fujisawa for valuable comments on symptoms of XT11 by checking the photos. This research was financially supported by the Grants-in-Aid for Scientific Research (\#21730593 to S. Inoue and \#24255010 to J. Yamagiwa) and the Grants-in-Aid for JSPS Fellows (\#14J00562 to T. Matsumoto).

\section{References}

Byrne RW, Stokes EJ (2002) Effects of manual disability on feeding skills in gorillas and chimpanzees. Int J Primatol 23:539-554

Doat D (2014) Evolution and human uniqueness: prehistory, disability, and the unexpected anthropology of Charles Darwin. In: Bolt D (ed) Changing social attitudes toward disability: perspectives from historical, cultural, and educational studies. Routledge, New York, pp 15-24

Fedigan LM, Fedigan L (1977) The social development of a handicapped infant in a free-living troop of Japanese monkeys. In: Chevalier-Skolnikoff S, Poirier FE (eds) Primate biosocial development: biological, social and ecological determinants. Garland, New York, pp 205-255

Goodall J (1986) The chimpanzees of Gombe: patterns of behavior. Harvard University Press, Cambridge

Hamada Y, Udono T, Teramoto M, Sugawara T (1996) The growth pattern of chimpanzees: somatic growth and reproductive maturation in Pan troglodytes. Primates 37:279-295

Hiraiwa-Hasegawa M (1990) A note on the ontogeny of feeding. In: Nishida T (ed) The chimpanzees of the Mahale mountains. Tokyo University Press, Tokyo, pp 277-283

Kumazaki K, Maeda N, Kato A, Suzuki J, Yamauchi S, Kaneko A, Goto S, Matsuzawa T (2010) Memories of Piko. In: Matsuzawa T (ed) What is human?. Iwanami, Tokyo, pp 110-111 (in Japanese)

Kummer H, Goodall J (1985) Conditions of innovative behaviour in primates. Philos Trans R Soc Lond B Biol Sci 308:203-214

McClure HM, Belden KH, Pieper WA, Jacobson CB (1969) Autosomal trisomy in a chimpanzee: resemblance to Down's syndrome. Science 165:1010-1012 
McClure H, Pieper W, Keeling M, Jacobson C, Schlant R (1973) Down's-like syndrome in a chimpanzee. In: Bourne GH (ed) The chimpanzee. University Park Press, Baltimore, pp 182-214

Nakamichi M (1986) Behavior of infant Japanese monkeys (Macaca fuscata) with congenital limb malformations during their first three months. Dev Psychobiol 19:335-341

Nakamichi M, Fujii H, Koyama T (1983) Behavioral development of a malformed infant in a free-ranging group of Japanese monkeys. Primates 24:52-66

Nakamura M (2010) What does it mean a society to be complex?: Questions about relationship between society and individual. Primate Res 26:131-142 (in Japanese with English summary)

Nakamura M, Hosaka K, Itoh N, Zamma K (eds) (2015) Mahale chimpanzees: 50 years of research. Cambridge University Press, Cambridge

Quiatt D, Reynolds V, Stokes EJ (2002) Snare injuries to chimpanzees (Pan troglodytes) at 10 study sites in East and West Africa. Afr J Ecol 40:303-305

Stokes EJ, Byrne RW (2001) Cognitive capacities for behavioural flexibility in wild chimpanzees (Pan troglodytes): the effect of snare injuries on complex manual food processing. Anim Cogn 4:11-28

Struhsaker TT, Chapman CA, Pope TR, Marcus JR (2011) Healthy baboon with no upper jaw or nose: an extreme case of adaptability in the Kibale National Park, Uganda. Primates 52:15-18

Sugiyama Y (1984) Population dynamics of wild chimpanzees at Bossou, Guinea, between 1976 and 1983. Primates 25:391-400

Sugiyama Y (2008) Birth of culture. Kyoto University Press, Kyoto (in Japanese)

Sugiyama Y, Kurita H, Matsui T, Kimoto S, Egawa J (2014) Congenital malformations in Japanese macaques (Macaca fuscata) at Takasakiyama. Primates 55:303-311

Turner SE, Gould L, Duffus DA (2005) Maternal behavior and infant congenital limb malformation in a free-ranging group of Macaca fuscata on Awaji Island, Japan. Int J Primatol 26:1435-1457

Turner SE, Fedigam LM, Nobuhara H, Nobuhara T, Matthews HD, Nakamichi M (2008) Monkeys with disabilities: prevalence and severity of congenital limb malformations in Macaca fuscata on Awaji Island. Primates 49:223-226

Turner SE, Fedigan LM, Matthews HD, Nakamichi M (2014) Social consequences of disability in a nonhuman primate. J Hum Evol 68:47-57

Wilson JG, Gavan JA (1967) Congenital malformations in nonhuman primates: spontaneous and experimentally induced. Anat Rec 158:99-109 